\title{
Comparative study on seismic response of vertically irregular RC buildings
}

\author{
Aboli A. Deshpande ${ }^{1}$, S. B. Shinde ${ }^{2}$, S. M. Dumne ${ }^{3}$ \\ ${ }^{1}$ (Post graduate student, Civil Engg. Department, Jawaharlal Nehru Engineering College, Aurangabad) \\ ${ }_{2}^{2}$ (Associate Professor and Head, Civil Engg. Department, Jawaharlal Nehru Engineering College, Aurangabad) \\ ${ }_{3}^{3}$ (Lecturer, Applied Mechanics Department, Government polytechnic Aurangabad)
}

\begin{abstract}
This study contains four models of RC Building of regular, mass irregular, stiffness irregular and soft storey. The peak responses of irregular building models are compared with Peak responses of regular building model. This building model contains ten stories modeled as shear type lumped mass system with single degrees of freedom at each floor level. The governing equation of motion is solved using Numark's method and is solved using coding in MATLAB software. From numerical results it is stated that peak responses of soft storey model gives better control over structural responses under various earthquakes except in some models.
\end{abstract}

Keywords: Seismic response, Regular building, Irregular building, Peak responses,.

\section{Introduction}

Many times the structures are of irregular in configuration both in elevation and plan which may prone to damage during earthquake. These irregularities may vary in their nature and principle, are very difficult to define. Assessment of structural performance during past earthquakes demonstrates that these types of irregularities due to asymmetrical distribution of mass, stiffness vertically is one of the most frequent sources of severe damage. A storey in a building is said to be a mass irregular if its mass exceeds $200 \%$ than that of the adjacent story. Similar to this if the stiffness and the strength of a story are less than $70 \%$ of those of the adjacent story, then a storey is said to contain the stiffness and strength irregularities. In such a case, the storey is termed as 'weak storey', and if lateral strength and stiffness irregularity is $80 \%$ or above, then the storey is termed as 'soft storey'.

In relevant to above study many past researchers have established the research findings but few of them are well outlined and reviewed. Stefeno and Pintucchi [1] (2008) presented an overview of the progress in research regarding seismic response of plan and vertically irregular structures. Ravikumar, et al [2] (2012) examined the effect of three different lateral load patterns on performance of various irregular buildings in pushover analysis. This study creates awareness about seismic vulnerability concept on practicing engineers. S. Varadharajan,V. K. Sehgal and Babita Saini [3] (2012) in this study single parameter to quantify mass, stiffness and strength irregularity in terms of both magnitude and location is proposed on the basis of the dynamic characteristics of the building. Furthermore, building models with different types of irregularity with variation in magnitude and location of irregularity are analyzed by subjecting them to an ensemble of 27 ground motions to create a seismic response databank. Jaswant N. Arlekar et al [4] (1997) This study depicts for immediate measures to prevent the indiscriminate use of soft first storeys in buildings, which are designed without regard to the increased displacement, ductility and force demands in the first storey columns. Alternate measures, involving stiffness balance of the open first storey and the storey above, are proposed to reduce the irregularity introduced by the open first storey it is concluded that hazardous feature of Indian RC frame buildings needs to be recognized immediately, and necessary measures taken to improve the performance of the buildings. Devesh P. Soni and Bharat B. Mistry [5] (2006) in their study the authors summarizes state-of-the-art knowledge in the seismic response of vertically irregular building frames. It is observed that building codes provide criteria to classify the vertically irregular structures and suggest dynamic analysis to arrive at design lateral forces and the largest seismic demand is found for the combined-stiffness-and-strength irregularity.

Irregular buildings are unavoidable due to functional and architectural requirements therefore it need to study in these areas. This study considered the objectives as (i) Determination of seismic response of various building models. (ii) Compare the peak responses of various irregular building models with regular model.(iii) Identifying most effective building model in seismic performance during earthquake.

\section{Problem Identification}

A structural model of lumped mass system having 5\% of damping with ten storey's of RC building in which each floor mass as 1219.129 ton and stiffness equal to $8.537 \mathrm{E}+06 \mathrm{KN} / \mathrm{m}$, respectively, which gives fundamental period of fixed base building with regular model as 0.502 seconds as shown in figure 1 . 


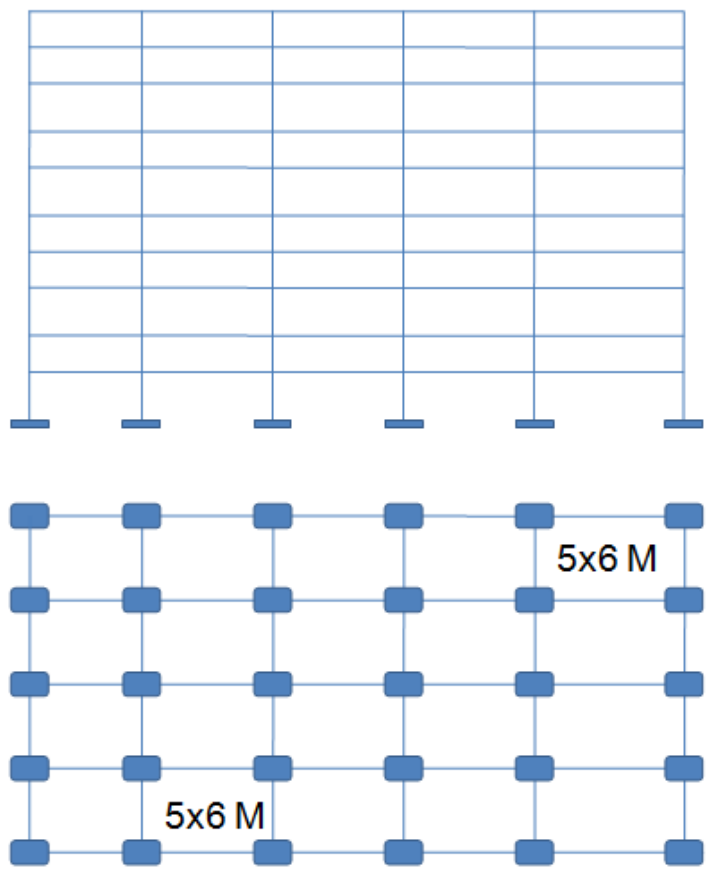

Figure 1. Plan and elevation of regular building model

\section{Structural Models}

Four different building models are idealized as a linear shear type lumped mass with single lateral degrees of freedom at each floor levels of which one regular building model is shown in figure 2 . The structural building models are assumed to remain in linear elastic state, therefore, does not yield during excitation. The numerical study has been performed corresponding to unidirectional excitation due to four real earthquakes. During this study, it is assumed that spatial variation of ground motion and also effect due to soil structure interaction is neglected. The governing equations of motion for multi degrees-of-freedom building are expressed in matrix form as:

$$
[M]\{\ddot{u}\}+[C]\{\dot{u}\}+[K]\{u\}=-[M]\{r\} \ddot{u}_{g}
$$

Where, $[M],[C]$ and $[K]$ are the mass, damping and stiffness matrices of the building respectively, $\{\mathrm{u}\}=\left\{\mathrm{u}_{\mathrm{b}}, \mathrm{u}_{1}, \mathrm{u}_{2}, \mathrm{u}_{3} \ldots \ldots \mathrm{u}_{\mathrm{N}}\right\},\{\dot{u}\}$ and $\{\ddot{u}\}$ are the vectors of relative floor displacement, velocity and acceleration response respectively, $\ddot{u}_{g}$ is the ground acceleration due to earthquake, $\{r\}$ is the vector of influence coefficient having all elements equal to one.

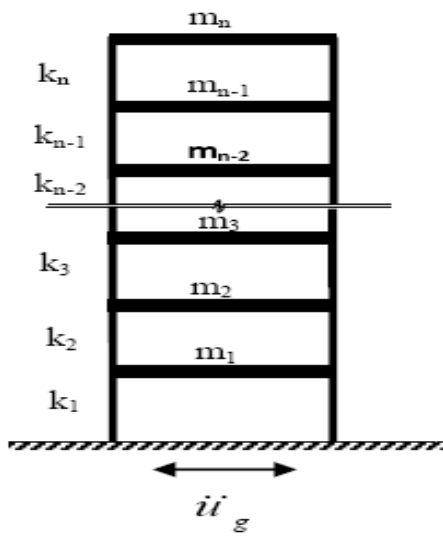

Figure 2. Structural model of regular building

\section{Numerical Study}

Four RC building models of ten storeys are considered for their performance in reducing responses during earthquake. First model is regular model in which mass is lumped at each floor equal to 1219.129 ton and that of stiffness $8.537 \times 10^{6} \mathrm{kN} / \mathrm{m}$. Second model is irregular in mass having mass of fifth floor equal to 916.77 ton whereas third model is irregular in stiffness having stiffness of last top five floors equal to $6.429 \times 10^{6} \mathrm{kN} / \mathrm{m}$ 
similarly, forth model is having soft storey with stiffness of the lower floor is $5.9 \times 10^{7} \mathrm{kN} / \mathrm{m}$. The building is subjected to unidirectional excitation for which four real earthquake ground motions are considered, details of which shown in Table 1.The seismic response of building has been simulated with the help of MATLAB platform.

Table 1 Details of earthquake ground motions

\begin{tabular}{|c|l|c|c|}
\hline Earthquake & \multicolumn{1}{|c|}{ Recording station } & Component & PGA(g) \\
\hline Imperial Valley & EI-centro & NO0E & 0.348 \\
\hline Loma Prieta & Loss gatos presentation centre & NOOE & 0.570 \\
\hline Kobe & Japan metrological Agency & NOOE & 0.834 \\
\hline Northridge & Sylmer converter center & NOOE & 0.843 \\
\hline
\end{tabular}

The peak response parameters of interest are, time varying top floor displacement $\left(u_{\mathrm{f}}\right)$, top floor acceleration $\left(a_{\mathrm{f}}\right)$, peak displacement response of top floor, peak acceleration response of top floor, peak storey shear and base shear.

\section{Results And Discussion}

The Table 2 shows the comparison of peak displacement response for top floor for various models. From these observations, it is concluded that top floor peak displacement for irregular building models is relatively more compared to regular model except in model 2. Peak displacement increases 11 to $13 \%$ for irregular model for imperial valley earthquake, 5 to $7 \%$ for loma prieta, however it decreases by 1 to $6 \%$ in kobe earthquake. Further, top floor peak acceleration response as mentioned in table 3 shows that decreasing pattern in values of irregular models than regular model. The top floor peak acceleration for model 4 is minimum and is 5 to $10 \%$ less than regular model for all earthquakes. From the observations mentioned in table 4 , it is noted that there is slightly decrease in base shear of all irregular building models as compared to regular building model under all earthquakes except Imperial Valley. Base shear decreases by 1 to $13 \%$ than regular model.

Table 2. Comparison of top floor peak displacement response of building models under various earthquakes

\begin{tabular}{|c|c|c|c|c|c|}
\hline Sr No & Earthquake & Model 1 & Model 2 & Model 3 & Model 4 \\
\hline 1 & $\begin{array}{c}\text { Imperial Valley, } \\
\text { 1940 (EQ 1) }\end{array}$ & 6.5922 & $6.3979(-2.94)$ & $7.4902(+13.64)$ & $7.3826(+11.98)$ \\
\hline 2 & $\begin{array}{c}\text { Loma Prieta, } \\
1989 \text { (EQ 2) }\end{array}$ & 15.1153 & $14.9679(-0.97)$ & $16.1676(+6.96)$ & $15.3951(+5.18)$ \\
\hline 3 & $\begin{array}{c}\text { Kobe, } \\
1995(E Q) ~ 3)\end{array}$ & 16.797 & $16.8033(+0.037)$ & $16.6238(-1.03)$ & $15.8994(-5.34)$ \\
\hline 4 & $\begin{array}{c}\text { Northridge, } \\
1994 \text { (EQ 4) }\end{array}$ & 15.8024 & $15.7837(-0.118)$ & $15.9943(+1.21)$ & $15.2757(+3.33)$ \\
\hline
\end{tabular}

Table 3. Comparison of top floor peak acceleration response of building models under various earthquakes

\begin{tabular}{|c|c|c|c|c|c|}
\hline Sr No & Earthquake & Model 1 & Model 2 & Model 3 & Model 4 \\
\hline 1 & $\begin{array}{c}\text { Imperial Valley, } \\
1940 \text { (EQ 1) }\end{array}$ & 1.1009 & $1.0961(-0.43)$ & $1.2009(+9.08)$ & $1.0253(-6.867)$ \\
\hline 2 & $\begin{array}{c}\text { Loma Prieta, } \\
1989 \text { (EQ 2) }\end{array}$ & 2.1986 & $2.1961(-0.115)$ & $2.4408(+11)$ & $2.069(-5.89)$ \\
\hline 3 & Kobe, 1995(EQ 3) & 2.7523 & $2.7897(+1.35)$ & $2.5366(-7.83)$ & $2.4781(-9.96)$ \\
\hline 4 & $\begin{array}{c}\text { Northridge, } \\
1994 \text { (EQ 4) }\end{array}$ & 2.5654 & $2.5963(+1.204)$ & $2.5255(-1.55)$ & $2.3301(-9.17)$ \\
\hline
\end{tabular}

Table 4. Comparison of normalized base shear response of building models under various earthquakes

\begin{tabular}{|c|c|c|c|c|c|}
\hline Sr No & Earthquake & Model 1 & Model 2 & Model 3 & Model 4 \\
\hline 1 & $\begin{array}{c}\text { Imperial Valley } \\
1940 \text { (EQ 1) }\end{array}$ & 0.7744 & $0.7395(-4.506)$ & $0.7877(+1.71)$ & $0.7989(+3.163)$ \\
\hline 2 & $\begin{array}{c}\text { Loma Prieta, } \\
1989 \text { (EQ 2) }\end{array}$ & 1.753 & $1.7315(-1.226)$ & $1.5921(-9.17)$ & $1.6522(-5.7)$ \\
\hline 3 & $\begin{array}{c}\text { Kobe, } \\
1995 \text { (EQ 3) }\end{array}$ & 1.8016 & $1.7874(-0.78)$ & $1.595(-11.46)$ & $1.5779(-12.41)$ \\
\hline 4 & $\begin{array}{c}\text { Northridge, } \\
1994 \text { (EQ 4) }\end{array}$ & 1.6519 & $1.6454(-0.39)$ & $1.475(-10.7)$ & $1.4871(-9.97)$ \\
\hline
\end{tabular}

Note: In the above all tables, braket value indicate the increase (+) or decrease (-) of peak responses in percentage of irregular models in comparison with regular model. 
Time varying top floor displacement is plotted in figure 3 for all building models, it is observed that top floor displacement under Imperial Valley and Northridge earthquakes is maximum at beginning of earthquake whereas for model 3, it seems to be maximum. It is also observed that variation of top floor displacement for all models is almost same with slight increment or decrement in response and same trend has been observed for top floor acceleration response as shown in figure 4.

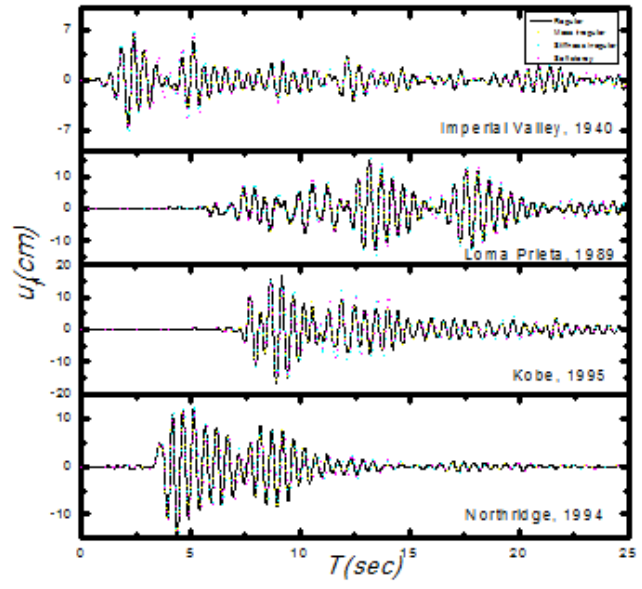

Figure 3. Top floor displacement

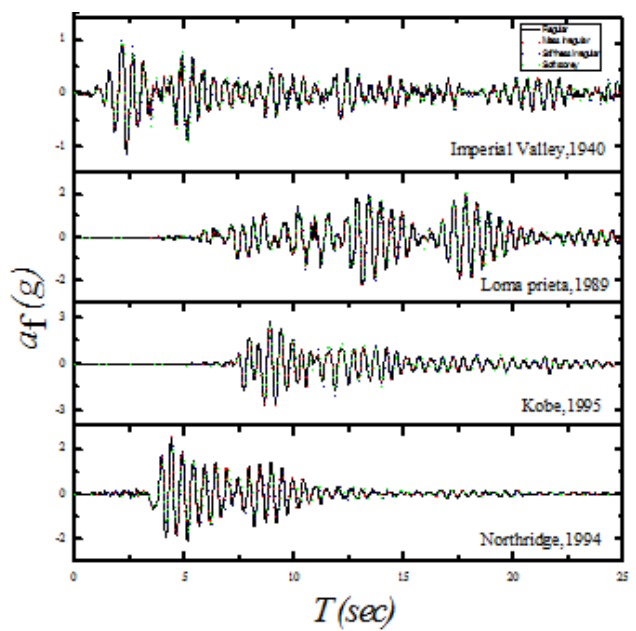

Figure 4. Top floor acceleration

Figure 5 shows the variation of base shear for all building models, it is observed that there is slight decrease in base shear of all building models with following same trend of variation. From figure 6 it is noted that peak displacement response is maximum in model 4 and minimum in model 3 except Imperial Valley whereas similar trend in variation of response for model 2 as observed in regular model.

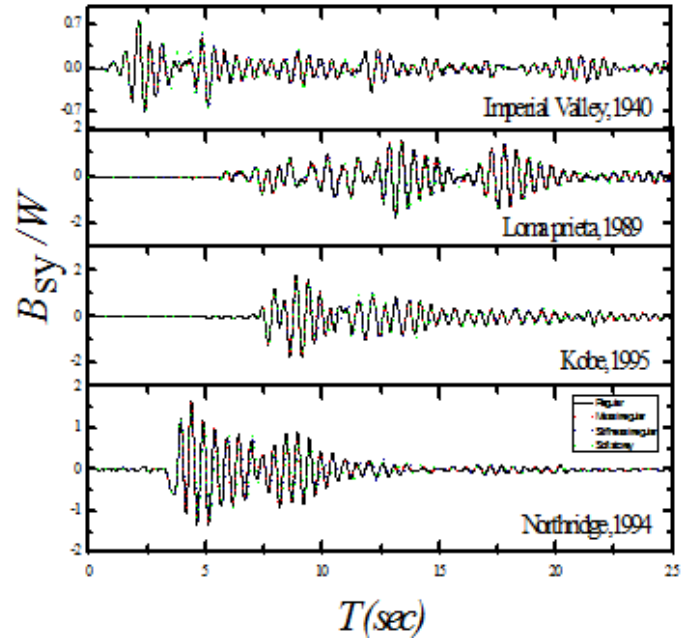

Figure 5. Time variation of base shear responses

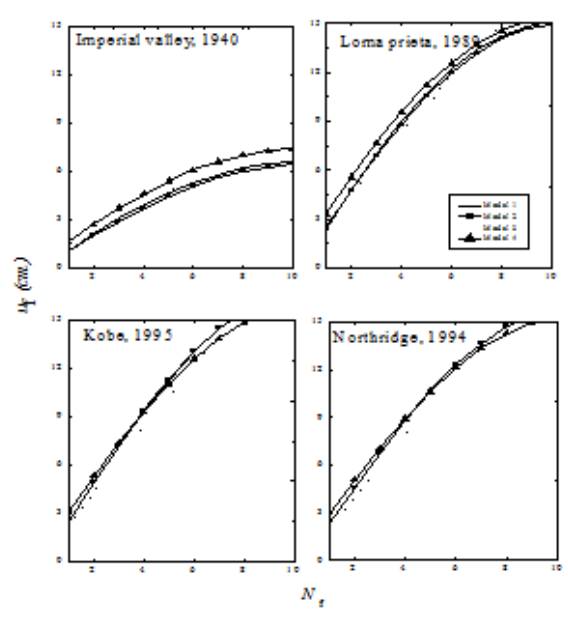

Figure 6. Peak floor displacement

From figure 7, it is clear that Peak floor acceleration is maximum in model 2 and minimum in model 4, however in Loma prieta earthquake model 3 shows variation from minimum to maximum value. The variation of peak storey shear for various building models is shown in figure 8 . From this figure, it is clear that there is continuous decrease in storey shear with respect to floor/ storey number. However one can comment that decrease in storey shear have similar trend for all building models but decrease in magnitude as compared to regular model. 


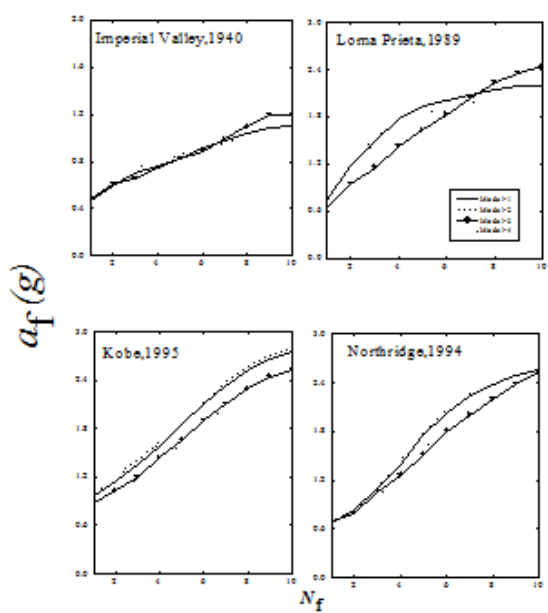

Figure 7. Peak floor acceleration

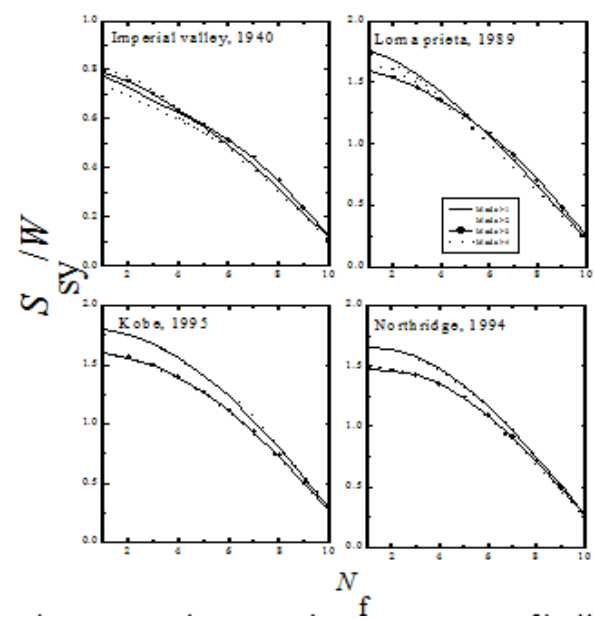

Figure 8. Peak storey shear responses of building models

\section{Conclusion}

This study proposed four models of ten storied RC Building with different characteristics. The comparison of peak responses of each irregular building model with regular model under excitation due to various earthquakes is studied. From numerical results, following concluding remarks are outlined

1. Top floor peak displacement response with mass irregular model is shows similar characteristics as regular model.

2. Top floor peak acceleration is minimum in soft storey model, hence it is concluded to be most effective amongst all irregular models.

3. Base shear of various building models is found decreasing except in some models as compared to regular model.

4. Peak storey shear is continuously goes on decreasing as floors increases and observed similar trends for all various building models, however storey shear get decreases in irregular models than regular model.

\section{References}

[1] M Stefeno, B. Pintucchi, A review of research on seismic behaviousr of irregular building structures since 2002, Bull Earthquake Engineering journal, 2008, 285-308 (1)

[2] C M Ravikumar, K S Bbunarayan,Sujit B V, Venkat Reddy D, Effect of irregular configuration on seismic volunerablity of RC Buildings, Architecture Research,2(3), 2012, 20-26. (2)

[3] S. Varadharajan, V. K. Sehgal and Babita Saini, Seismic response of multistory reinforced concrete frame with vertical mass and stiffness irregularities, published online in Wiley Online Library (wileyonlinelibrary.com/journal/tal). DOI: 10.1002/tal.1045.(3)

[4] Devesh P. Soni* and Bharat B. Mistry, qualitative review of seismic response of vertically Irregular building frames ISET Journal of Earthquake Technology, Technical Note, Vol. 43, No. 4, December 2006, pp. 121-13.(5)

[5] Jaswant N. Arlekar, Sudhir K. Jain and C.V.R. Murty, Seismic Response of RC Frame Buildings with Soft First Storeys, Proceedings of the CBRI Golden Jubilee Conference on Natural Hazards in Urban Habitat, 1997, New Delhi.(4) 